\title{
PELESTARIAN KEARIFAN LOKAL MELALUI PELATIHAN MENDONGENG BAGI BUNDA P.A.U.D. KELURAHAN DR. SOETOMO, SURABAYA
}

\author{
Samuel Gunawan ${ }^{*}$, Jenny M. Djundjung' Meilinda $^{3}$ \\ 1,2,3 Fakultas Sastra, Universitas Kristen Petra \\ Jl. Siwalankerto 121-131, Surabaya 60236 \\ * Penulis korespondensi; Email: samgun@petra.ac.id
}

\begin{abstract}
Abstrak: Kegiatan Pengabdian kepada Masyarakat (PkM) yang dibiayai dana hibah skema program Ipteks bagi masyarakat $\left(\mathrm{I}_{b} \mathrm{M}\right)$ sebagaimana dilaporkan di sini dilaksanakan untuk menjawab kebutuhan nyata khalayak sasaran berupa pelatihan kompetensi mendongengkan cerita rakyat Nusantara bagi para bunda dan calon bunda PAUD. Kompetensi yang semakin langka dan terpinggirkan seiring dengan kemajuan media komunikasi modern pada umumnya ini sangat diperlukan bagi para bunda dan calon bunda yang tergabung dalam kegiatan Pendidikan Anak Usia Dini (PAUD) di lingkup Kelurahan Dr. Soetomo, Surabaya. Dengan adanya pelatihan ini diharapkan para bunda dan calon bunda PAUD khalayak sasaran dapat memiliki kompetensi mendongengkan cerita-cerita rakyat Nusantara yang merupakan kearifan lokal sebagai media pendidikan karakter bagi anak-anak asuh di PAUD setempat. Kegiatan PkM serupa juga sangat bermanfaat bilamana dapat disebarluaskan di khalayak sasaran lainnya yang sangat membutuhkan di jantung kota Surabaya.
\end{abstract}

Kata kunci: Mendongeng, pendidikan karakter, Kearifan lokal, PAUD

\begin{abstract}
The Community Service Project funded by the Higher Education IbM grant as reported here was conducted in order to meet the real need of the focus group in terms of training attendants of Early Childhood Education (ECE) in Kelurahan Dr Soetomo, Surabaya to have the competence to tell Nusantara folk tales These skills of storytelling that have been rare and marginalized by the advancement modern means of communication were badly needed by attendants or would-be attendants who are organized under Early Childhood Education (ECE). Through the training, ECE attendants will be enabled to tell Nusantara folktales which are rich in local wisdom as a media of character education for todlers in the local ECE. Such a community service project could also be beneficial if it is disseminated in other focus groups that badly need it in the inner city of Surabaya.
\end{abstract}

Keywords: Storytelling, character education, local wisdom, Early Childhood Educatiob.

\section{PENDAHULUAN}

Surabaya sebagai kota metropolitan terbesar kedua di Indonesia berkembang dengan pesat. Namun kemajuan tersebut juga membawa serta efek sampingan beberapa permasalahan lingkungan kehidupan sosial warga masyarakatnya. Perkembangan demikian sering disertai luntur dan rusaknya akarakar kearifan lokal di lingkungan komunitas warga kota. Di antara nilai-nilai tradisi dan kearifan lokal yang menjadi fokus Pengabdian kepada Masyarakat (seterusnya PkM) yang dilaksanakan disini ialah gejala semakin langkanya tradisi dan keterampilan mendongeng untuk anak-anak di kalangan orang tua perkotaan di jantung kota seperti Surabaya (lihat Husnaini, 2011). Pesatnya partum- buhan kehidupan perkotaan, namun tidak diiringi upaya pelestarian nilai-nilai kearifan lokal warga masyarakat yang demikian itu, kalau dibiarkan akan terus menerus menggerus nilai-nilai kearifan lokal yang ada dalam kehidupan komunitas perkotaan seperti di jantung kota Surabaya. Bila tidak ada intervensi positif dari para pemangku kepentingan, maka akan terjadi semakin kering kerontangnya roh kehidupan batiniah warga masyarakat, khususnya bakal generasi muda, karena teralinasinya nilai-nilai kearifan lokal positif yang sebenarnya merupakan bagian dari kekayaan khazanah budaya lokal yang berguna bagi pendidikan karakter anak-anak usia dini (lihat Balai Melayu, 2013; Kusuma dan Suwarna, 2011; Jaenudin, 2008). 


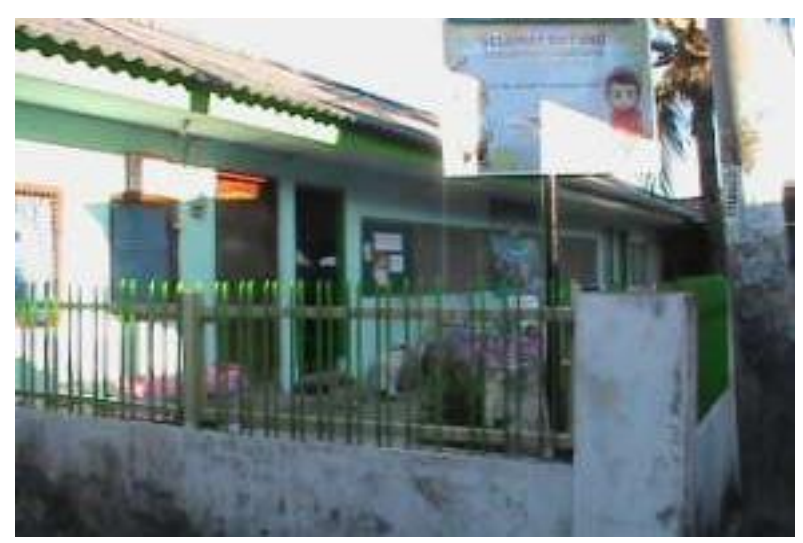

Gambar 1. Balai RW 03 Kelurahan Dr. Soetomo

Kelurahan Dr. Soetomo, Kecamatan Tegalsari, Surabaya, yang merupakan bagian dari jantung kota Surabaya, merupakan kelompok sasaran $\mathrm{PkM}$ yang kemajuannya dilaporkan di sini. Di sebagian kecil dari komunitas khalayak sasaran ini, aitu bertempat di RW 03, Kelompok Pelaksana PkM telah merintis kerjasama dengan pihak Kelurahan setempat, khususnya melalui kegiatan PkM Hibah Dikti th. 2013 berupa pendampingan/pelatihan Bahasa Inggris berbasis pendidikan karakter untuk Kelompok Bermain Anak RW 03 yang melibatkan para dosen Prodi Sastra Inggris U.K. Petra, para Bunda Pendidikan Anak Usia Dini (seterusnya PAUD) setempat, dan para mahasiswa U.K. Petra. Kemudian Tim yang sama juga telah melaksanakan kegiatan PkM berupa "Pelatihan mendongeng bagi bunda PAUD RW 03, Kelurahan Dr. Soetomo", dengan dukungan dana PkM internal Universitas Kristen Petra th. 2014. Berdasarkan permintaan dan kebutuhan yata di komunitas khalayak sasaran, yaitu yang mencakupi keseluruhan kelurahan Dr. Soetomo serta berpedoman pada kegiatankegiatan PkM sebelumnya, kegiatan PkM th. 2015 yang dilaporkan di sini dilaksanakan untuk memberi pelatihan keterampilan mendongengkan ceritacerita rakyat Nusantara kepada para bunda dan calon bunda dari keseluruhan PAUD-PAUD di keseluruhan lingkup kelurahan Dr. Soetomo, Surabaya

\section{PERMASALAHAN MITRA}

Permasalahan yang dihadapi oleh khalayak sasaran adalah: masih langkanya keterampilan mendongengkan cerita-cerita rakyat Nusantara tematik berbasis pendidikan karakter di kalangan bunda dan calon bunda PAUD.

Keterampilan yang ditargetkan di sini merupakan kontribusi nyata ke arah "Surabaya Kota Layak dan Ramah Anak" dan pelestarian kekayaan kearifan lokal khazanah budaya bangsa berupa tradisi mendongeng.

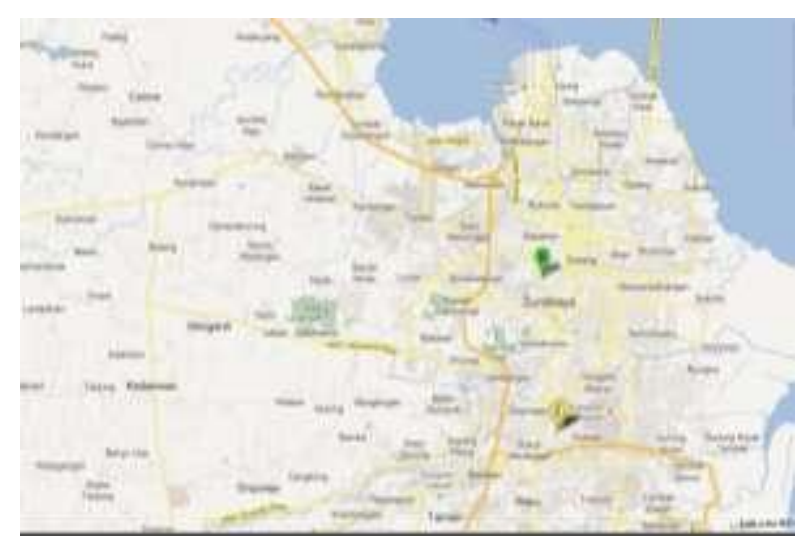

Gambar 2. Lokasi Pengabdian kepada Masyarakat di jantung kota Surabaya

\section{METODE PELAKSANAAN}

Tim PkM dengan mensinergikan keahlian antar disiplin ilmu, pengalaman, dan dedikasinya, berusaha menggerakkan kekuatan secara bottom up bersama-sama para pemangku kepentingan khalayak sasaran untuk melakukan tindakan konkrit pelatihan dan pendampingan untuk pemberdayaan bunda dan calon bunda PAUD di keseluruhan lingkup Kelurahan Dr. Soetomo melalui langkahlangkah konkrit sbb.:

1) Memberi pelatihan/pendampingan mendongengkan cerita-cerita rakyat Nusantara tematik berbasis pendidikan karakter bagi bunda dan calon bunda PAUD di keseluruhan lingkup Kelurahan Dr. Soetomo, Surabaya.

2) Memberi pelatihan/pendampingan dalam mempersiapkan alat peraga mendongengkan ceritacerita rakyat yang dibuat dari bahan daur ulang.

3) Melibatkan para bunda PAUD RW 3, Kelurahan Dr. Soetomo, yang pernah dilatih dan dipersiapkan sebelumnya melalui pelatihan/pendampingan TOT (training of trainer) yang didanai PkM internal U.K. Petra th. 2014 agar berperan sebagai sebagai pendamping.

4) Menyelenggarakan unjuk kebolehan keterampilan mendongengkan cerita-cerita rakyat Nusantara tematik berbasis pendidikan karakter bagi para peserta pelatihan / pendampingan PkM.

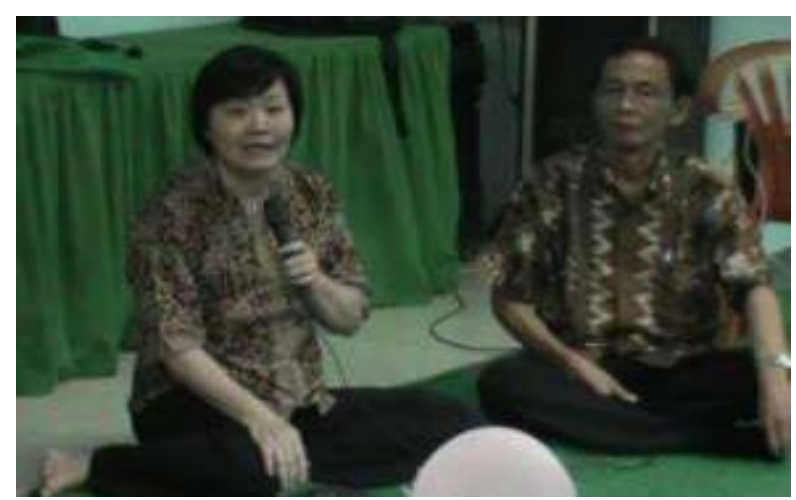

Gambar 3. Dr. Jenny M. Djundjung, MA mengajak para bunda berbagi pengalaman tentang mendongeng sebagai media pendidikan karakter 
Dongeng-dongeng yang dipergunakan dalam pelatihan PkM ini dipilih secara khusus berupa dongengdongeng tematik yang menitikberatkan tata nilai kearifan lokal untuk pendidikan karakter anak usia dini. Untuk itu pemilihan dongeng-dongeng tersebut didasarkan pada totalitas psikologis yang mencakup seluruh potensi individu anak-kognitif, afektif, dan psikomotorik (lihat Lickona, 1991) dan fungsi totalitas sosiokultural dalam konteks interaksi dalam keluarga, satuan pendidikan, dan masyarakat. Totalitas psikologis dan sosiokultural dapat dikelompokkan secara selektif sebagaimana yang digambarkan dalam bagan totalitas konfigurasi pendidikan karakter (lihat Gambar 2).

Konfigurasi karakter dalam kontek totalitas proses psikologis dan sosial-kultural dapat dikelompokkan berupa: (1) Olah Hati (spiritual and emotional development); (2) Olah Pikir (intellectual development); (3) Olah Raga dan kinestetik (physical and kinesthetic development); dan (4) Olah Rasa dan Karsa (affective and creativity development).

\section{HASIL DAN PEMBAHASAN}

\section{Teknik dan Keterampilan mendongeng}

Setelah berkenalan dengan dimensi pendidikan karakter, para peserta pelatihan diajak memahami teknik dan keterampilan mendongeng yang disampaikan oleh Dr. Samuel Gunawan,MA. Untuk maksud tersebut digunakan sebuah dongeng yang digali dari khazanah tradisi lisan berupa dongeng "Joko Bodo". Disampaikan teknik dan keterampilan mendongeng sbb.:

\section{Ringkasan Dongeng}

* Bunda harus ingat ringkasan dongeng sbb:

\section{TOTOLET JOKO BODO}

- Mbok Rondo Dadapan mempunyai satu orang anak-namanya Joko Bodo. Joko Bodo ingin mempunyai cempe (anak kambing). Mboknya tidak mempunyai uang cukup untuk membeli cempe.

- Pada suatu hari Joko Bodo bermain-main dan berenang di tepian sungai. Dia melihat ada cempe mati yang terhanyut di sungai. Dia ambil cempe tadi. Digendongnya, dibawa pulang.

- Dekat rumah, mbok Rondo melihat Joko Bodo menggendong cempe mati tadi. Cempe mati berbau tidak sedap. Mbok Rondo menyuruh Joko membuang cempe tadi. Cempe itu berbau tidak sedap karena cempe tadi sudah mati.

- Pada suatu hari Joko Bodo kembali bermainmain di tepi sungai. Perutnya terasa senep. Tak tertahan lagi, dia kentut habis-habisan. Karena baunya bukan main, dia menyangka dirinya sudah mati. Dia membuang dirinya ke sungai.

- Joko Bodo hanyut di air sungai. Beruntung Pak Lurah lewat dan melihat Joko yang terhanyut. Dia menyuruh pengawalnya untuk menyelamatkan Joko.

* Ringkasan sebagai alur utama baku (Pakem) bisa diperkaya dengan detil yang bervariasi (Carangan)

\section{TOTOLET JOKO BODO}

\section{- Persiapan}

Anak-anak, hari ini bunda mau mendongeng tentang Joko Bodo. Ini Joko Bodo-anak mbok Rondo Dadapan, bukan Ki Joko Bodo. Judul ceritanya: "Totolet Joko Bodo"

Apa, anak-anak, judul cerita bunda? Bagus, bagus, "Totolet Joko Bodo"

Bunda mau bertanya: Siapa diantara anak yang mau dibilang "bodo"? Ada yang mau? Baik, anak- anak semua tentu ingin pintar-tidak mau disebut "bodo", bodoh.

- Pembukaan

Ada sebuah desa yang sangat terpencil. Namanya desa Dadapan. Ada seorang janda namanya Mbok Rondo Dadapan. Mbok Rondo Dadapan mempunyai satu orang anak laki saja-namanya Joko Bodo. Joko Bodo ingin mempunyai cempe (anak kambing). Mboknya tidak mempunyai uang cukup untuk membeli cempe. Mboknya berjanji kalau ada cukup uang, Joko akan dibelikan cempe yang diinginkannya.

- Inti Dongeng

Pada suatu hari Joko Bodo bermain-main dan berenang di tepian sungai. Dia melihat ada cempe mati yang terhanyut di sungai. Joko Bodo anak yang sangat polos dan lugu. Dia tidak tahu apa cempe mati itu. Dia ambil cempe tadi.

Digendongnya, dibawa pulang. Sampai di dekat rumah, mbok Rondo melihat Joko Bodo datang sembari menggendong cempe mati tadi. Cempe mati berbau tidak sedap. Mbok Rondo menyuruh Joko membuang cempe tadi.

Cempe itu berbau tidak sedap karena cempe tadi sudah mati. Pada suatu hari Joko Bodo kembali bermain-main di tepi sungai. Dari rumah dia habis makan.

Mboknya hari itu membuat lauk botok sembukkan. Karena tadi makan kelewat kenyang, Joko sekarang merasa perutnya senep. Tak tertahan lagi, dia kentut habis-habisan: totolet, totolet, totolet ... dut !! Karena baunya bukan main, dia menyangka dirinya sudah mati. Dia membuang dirinya ke sungai. 
- Penutup

Joko Bodo hanyut di air sungai. Beruntung Pak Lurah lewat dan melihat Joko yang terhanyut. Dia menyuruh pengawalnya untuk menyelamatkan Joko.

Joko Bodo jadi mengerti dia bau bukan main karena dia kentut habis-habisan. Dia mengerti dia mengeluarkan bau, tapi dia tidak mati.

- Follow up

Beberapa pertanyaan seputar dongeng yang berfokus pada hikmah/nilai-nilai positip yang bisa didapat dari dongeng tadi.

\section{Strategi dan Penyuaraan dalam Mendongeng}

Bu Meilinda, S.S., M.A., melatih peserta membuat rancang bangun dongeng secara sederhana dan sistematik yang sangat membantu proses pendongengan. Dilatihkan pula teknik penyuaraan karakter dalam mendongeng agar membuat kegiatan mendongeng menjadi lebih hidup dan menarik.

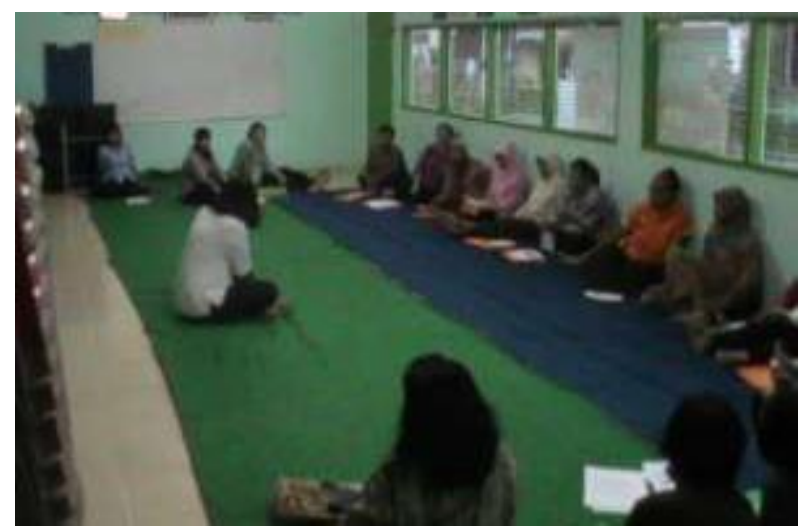

Gambar 5. Bu Meilinda, S.S., M.A. melatih strategi mendongeng

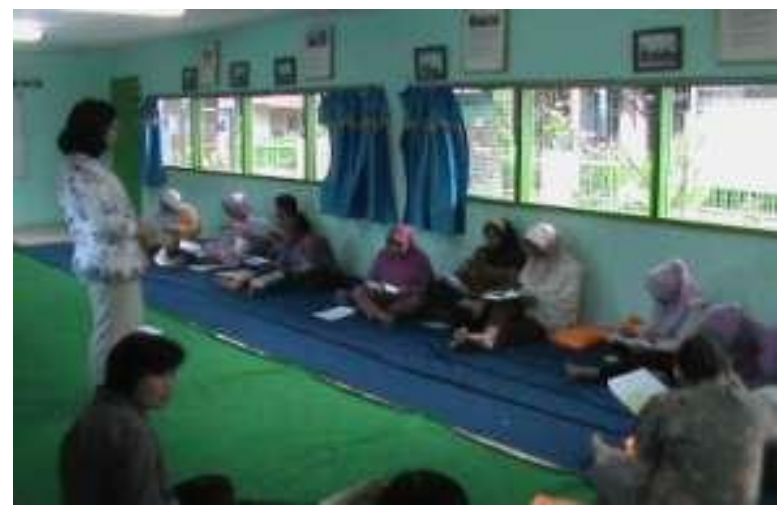

Gambar 6. Menyimak materi pelatihan

\section{Pelatihan Membuat Media/Alat Peraga Mendongeng}

Kepada para peserta juga dilatihkan keterampilan membuat media mendongeng/alat peraga di bawah asuhan Bu Aniendya Christianna, S.Sn, M. Med.
Kom. Berdasarkan masukan dan permintaan para peserta alat peraga yang mereka persiapkan adalah diperuntukkan 3 macam dongeng:

1. Dongeng Gajah dan Semut.

2. Dongeng Bawang Merah dan Bawang Putih.

3. Dongeng Keong Mas.

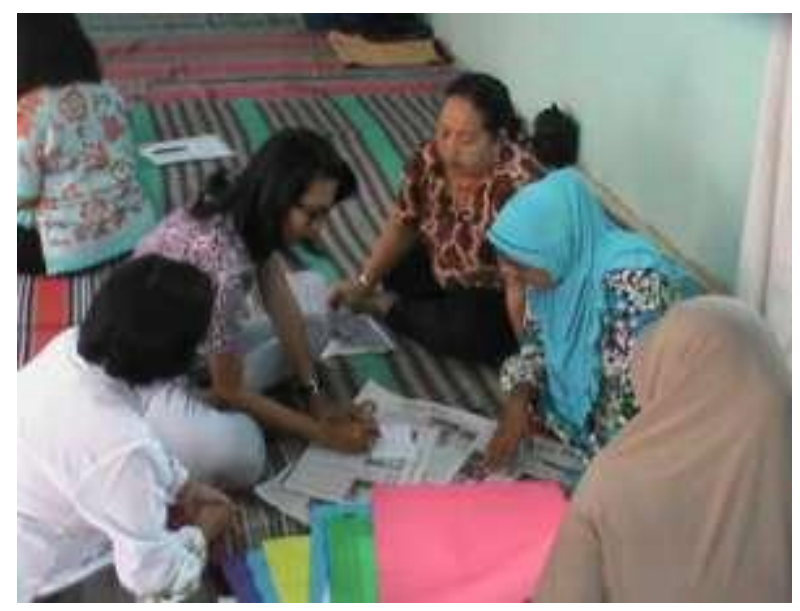

Gambar 7. Merancang alat peraga mendongeng

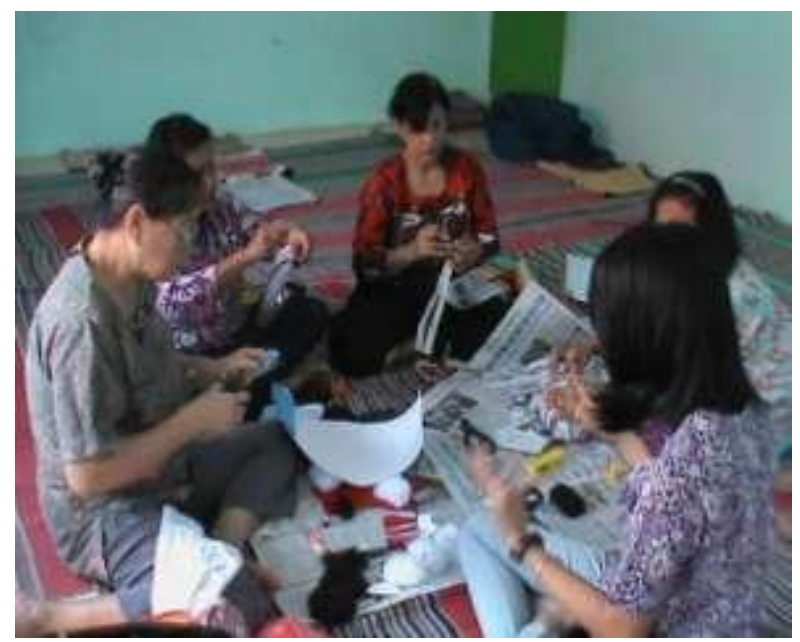

Gambar 8. Menyiapkan alat peraga mendongeng

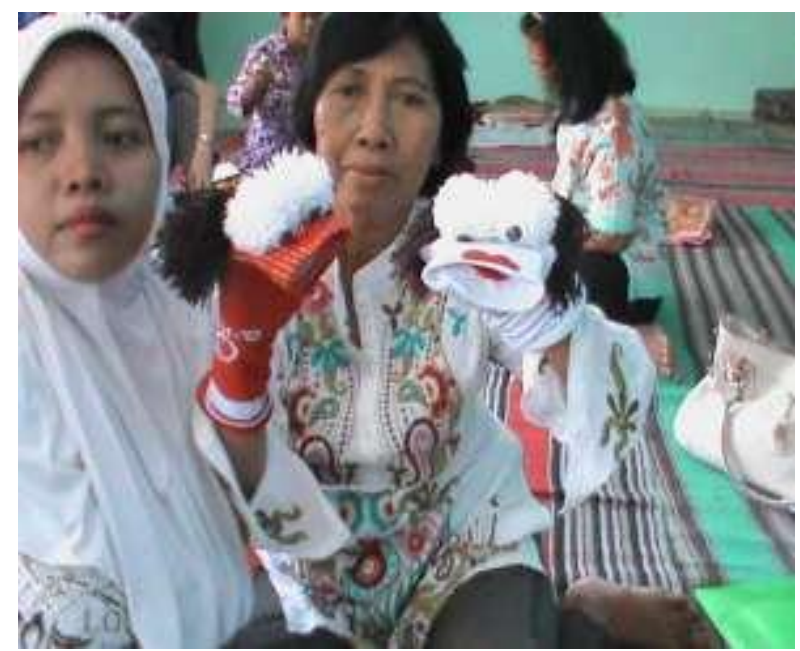

Gambar 9. Alat peraga untuk dongeng "Bawang Merah dan Bawang Putih" 


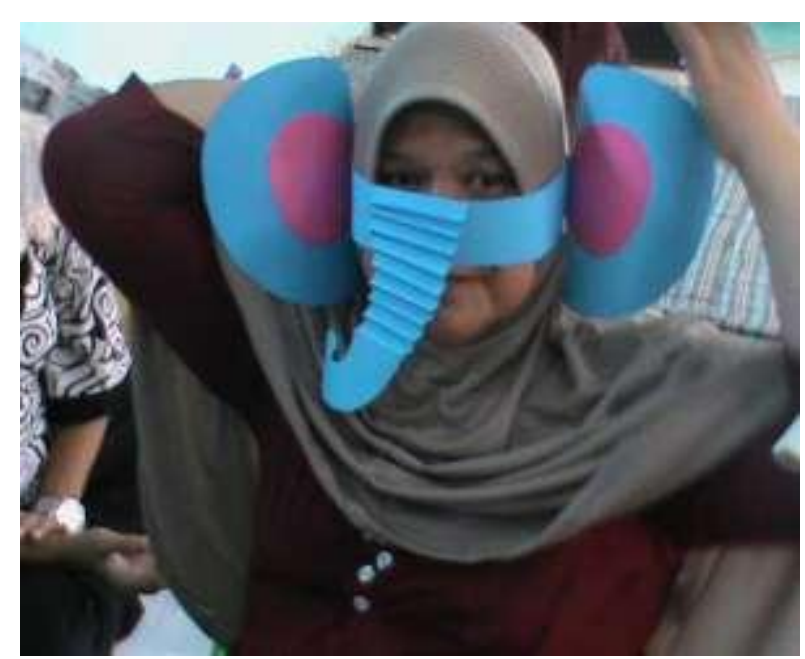

Gambar 10. Alat peraga dongeng "Gajah dan Semut"

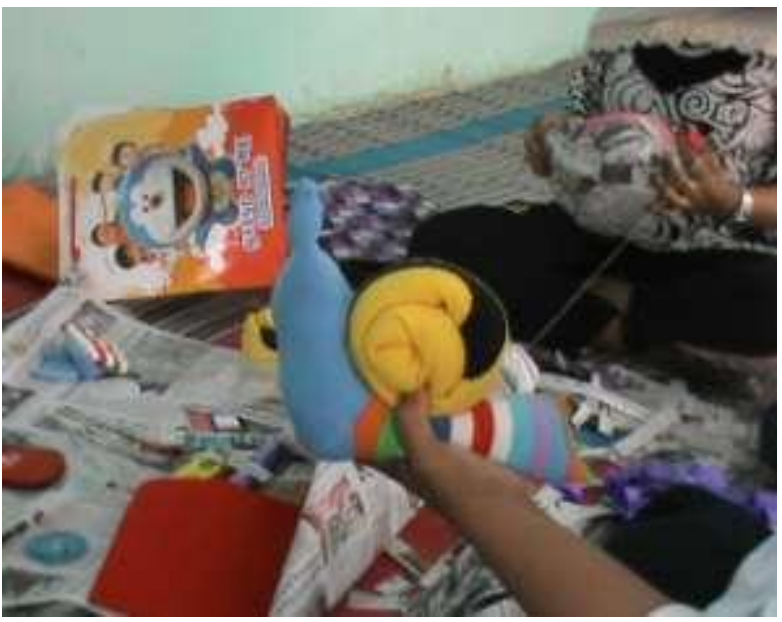

Gambar 11. Membuat alat peraga dongeng "Keong Mas"

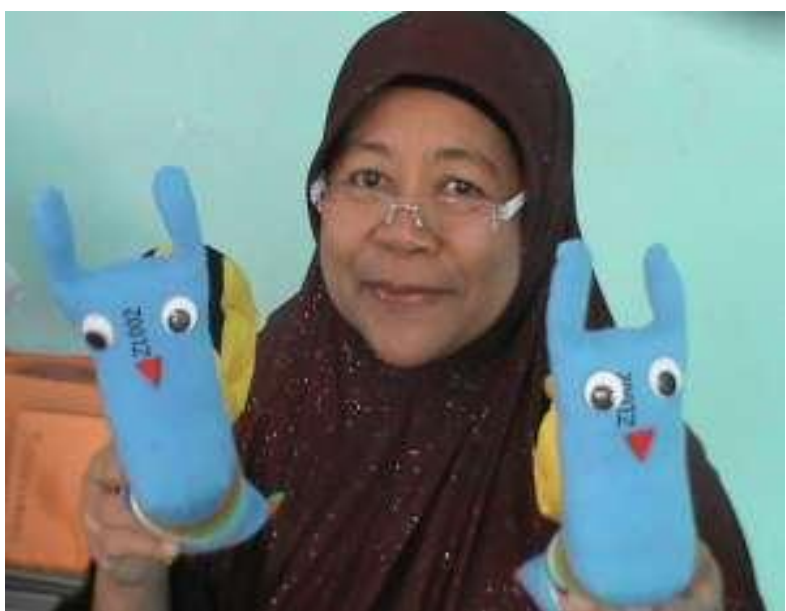

Gambar 12. Alat peraga dongeng "Keong Mas"

\section{Praktikum Mendongeng}

Setelah menyiapkan media/alat peraga untuk 3 dongeng tersebut di atas, masing-masing kelompok diberi kesempatan untuk melaksanakan praktikum mendongeng. Mereka sekaligus diminta menggunakan alat peraga yang sudah mereka persiapkan.

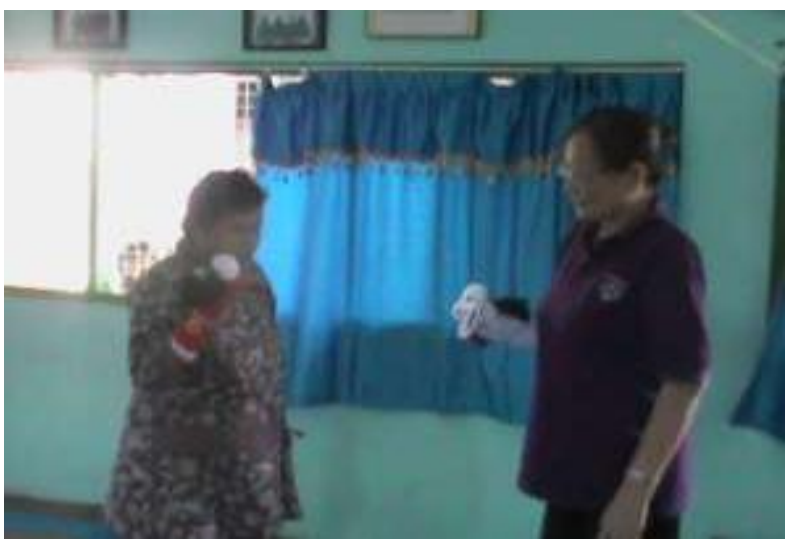

Gambar 13. Praktikum dongeng "Bawang Merah dan Bawang Putih" dengan alat peraga

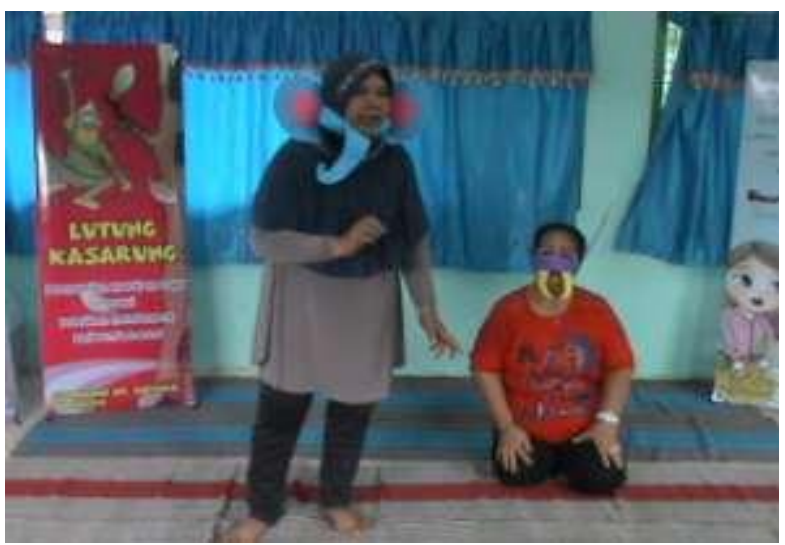

Gambar 14. Mendongeng “Gajah dan Semut

\section{Lomba Keterampilan Mendongeng}

Untuk memberi kesempatan unjuk kebolehan mendongeng serta menggunakan alat peraga kepada para peserta pelatihan, Team PkM menyelenggarakan Lomba Keterampilan Mendongeng yang diikuti oleh para peserta pelatihan pada tgl 2 Juli 2015. Dalam kesempatan ini peserta secara berpasangan melakukan unjuk kebolehan mendongeng dan menggunakan alat peraga yang mereka telah persiapkan sesuai tema dongeng. Terdapat sebanyak 7 kelompok pendongeng.

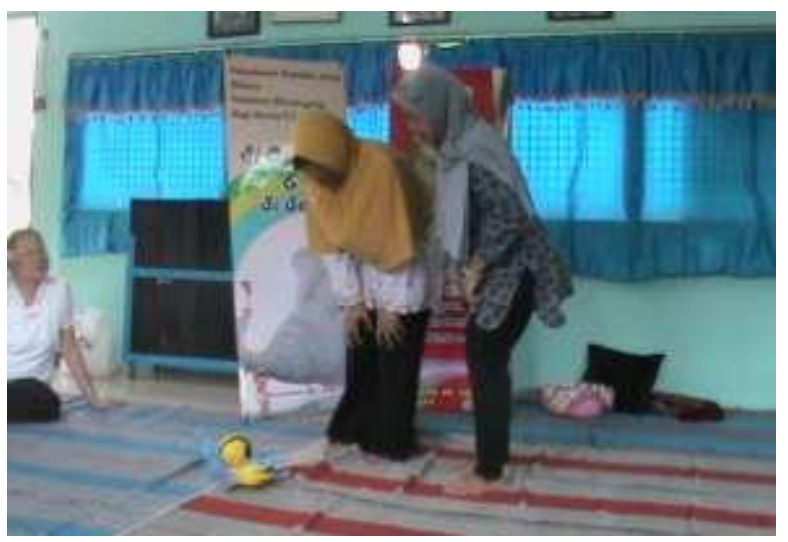

Gambar 15. Dongeng "Keong emas" 
Untuk tetap mempraktekkan dan mengembangkan keterampilan-keterampilan mendongeng, kepada PAUD RW 03 sebagai pilot proyek pemberdayaan PAUD di lingkup Kelurahan Dr. Soetomo dalam kesempatan yang bersamaan telah diserahkan seperangkat rumah boneka sebagai sarana untuk kegiatan mendongeng.

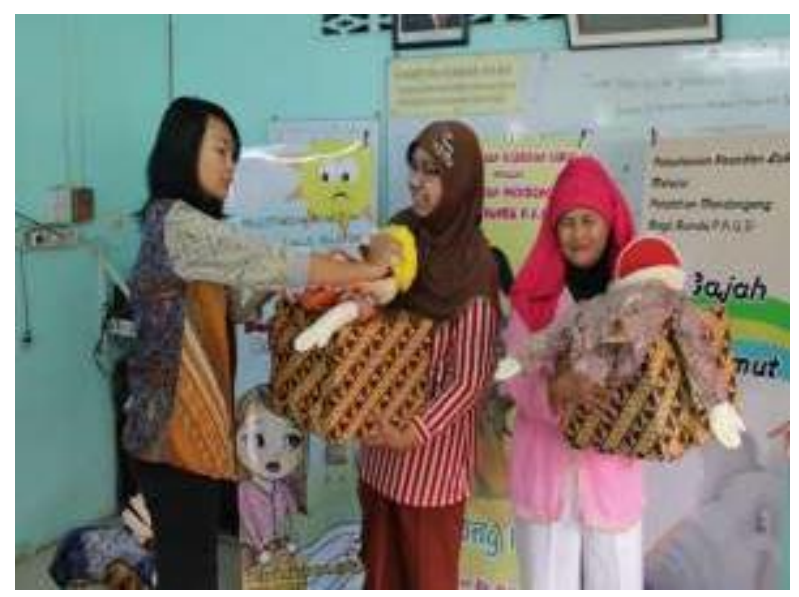

Gambar 16. Penyerahan hadiah bagi pemenang lomba unjuk kebolehan mendongeng

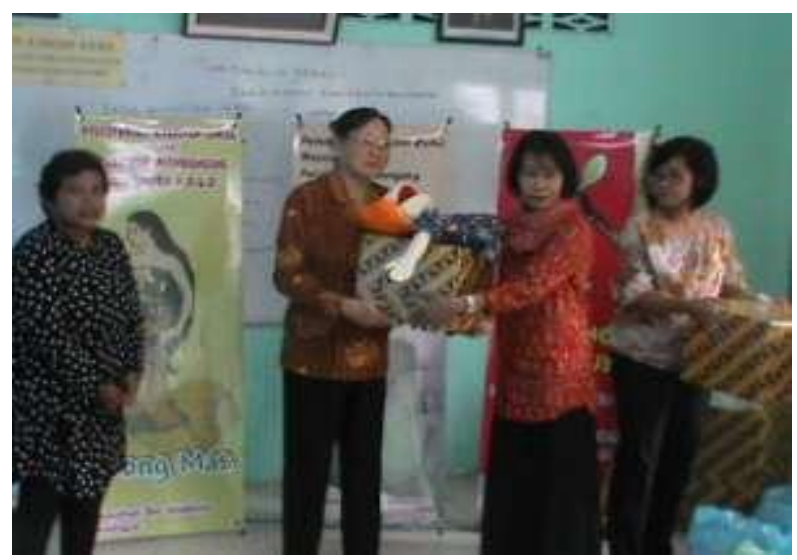

Gambar 17. Penyerahan hadiah bagi pemenang Ilomba unjuk kebolehan mendongeng oleh yg mewakili Lurah Kelurahan Dr. Soetomo

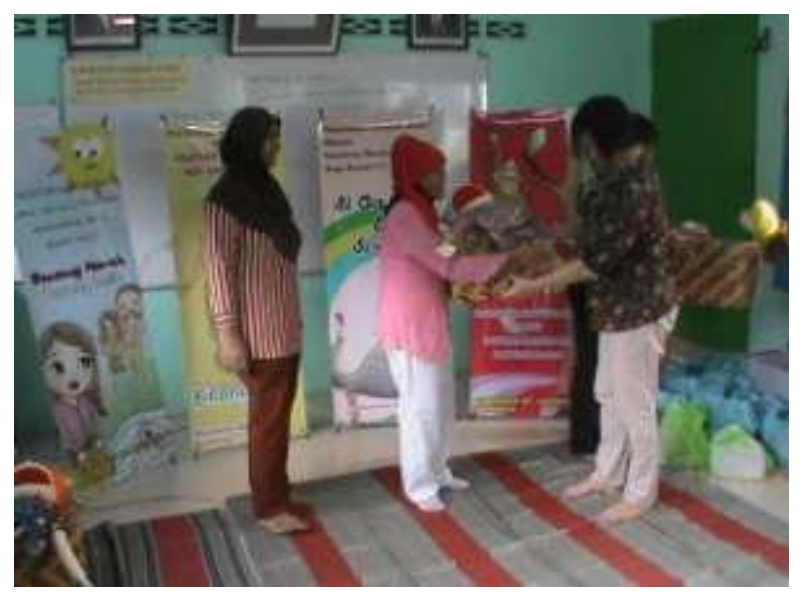

Gambar 18. Penyerahan hadiah bagi pemenang lomba unjuk kebolehan mendongeng

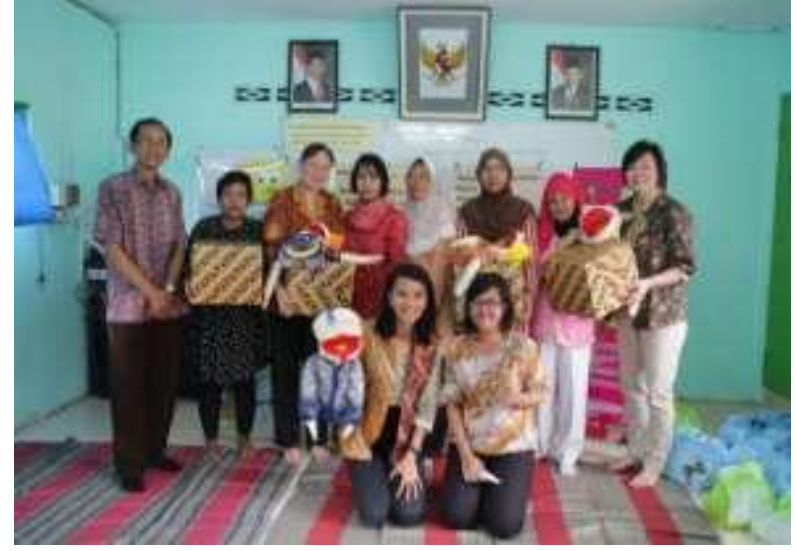

Gambar 19. Para pemenang lomba unjuk kebolehan mendongeng berpose bersama nara sumber

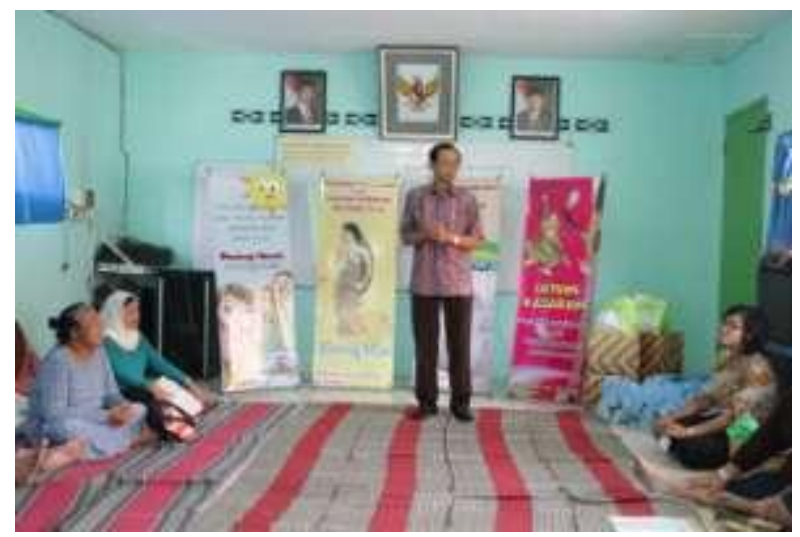

Gambar 20. Dr. Samuel Gunawan, MA, selaku ketua pelatihan, memberikan sambutan penutupan pelatihan

\section{KESIMPULAN DAN SARAN}

Dengan telah terlaksananya Pengabdian kepada Masyarakat yang didukung Dana Hibah program Ipteks bagi masyarakat $\left(\mathrm{I}_{b} \mathrm{M}\right)$, yang berjudul "Pelestarian Kearifan Lokal Melalui Pelatihan Mendongeng bagi Bunda P.A.U.D Kelurahan Dr. Soetomo, Surabaya" dapat ditarik beberapa kesimpulan dan saran sbb.

\section{Kesimpulan}

1. Masih banyak kelembagaan PAUD di daerah "kantong-kantong ketertinggalan sosial" di jantung kota Surabaya yang memerlukan pemberdayaan berbasis komunitas setempat dengan melibatkan para pakar dari perguruan tinggi. Dengan kata lain kegiatan PkM seperti yang dilaporlan di sini adalah bentuk kontribusi nyata perguruan tinggi dalam rangka penerapan IPTEKS tepat guna untuk kemaslahatan masyarakat.

2. Dengan terjalinnya hubungan antara tim pakar perguruan tinggi dengan khalayak sasaran dan para pemangku kepentingan melalui kegiatan $\mathrm{PkM}$, tindak lanjut kesinambungan kegiatan 
pemberdayaan bisa dirancang dan dilakukan, baik dengan dana lokal, dana pemerintah, maupun swadana setempat. Dengan demikian peluang partisipasi penerapan IPTEKS untuk ikut memajukan masyarakat semakin terbuka luas.

3. Inti dari kegiatan $\mathrm{PkM}$ yang dilaporkan di sini adalah pemberdayaan warga khalayak sasaran, yaitu para bunda PAUD, dengan keterampilan mendongengkan cerita-cerita rakyat Nusantara yang mengandung kearifan lokal bagi pendidikan karakter. Dengan kegiatan ini telah dihasilkan:

a. Kompetensi mendongengkan cerita-cerita rakyat Nusantara yang bermanfaat bagi pendidikan karakter sesuai kebutuhan khusus khalayak sasaran.

b. Unjuk kebolehan mendongengkan ceritacerita rakyat Nusantara dan beberapa bentuk pembelajaran kreatif yang dapat menghidupkan suasana kegiatan bermain dan belajar di PAUD.

c. Pendampingan terhadap bunda PAUD yang ujung-ujungnya berdampak pada pemberdayaan dan penguatan wawasan dan kompetensi mereka dalam berkegiatan di PAUD.

d. Penguatan lembaga PAUD pada kelompok sasaran.

e. Upaya nyata menggugah para pemangku kepentingan dan komunitas khalayak sasaran untuk berkontribusi ke arah tercapainya "situasi dan kondisi sosial yang lebih ramah dan layak anak" di komunitas setempat.

Kegiatan PkM yang telah dilaksanakan telah membawa manfaat memberi penguatan, pemberdayaan SDM, dan pencerahan kepada segenap pihak yang secara langsung dan tidak langsung terlibat dalam kegiatan ini. Ibarat gading tidak ada yang tidak retak, kegiatan pengabdian kepada masyarakat yang telah dilakukan dan dilaporkan ini tak lepas dari berbagai kekurangan di sana sini. Oleh sebab itu bentuk kegiatan PkM ini sebagai salah satu prototipe kegiatan PkM terbuka untuk dikritik yang sifatnya membangun dan perlu terus disempurnakan demi meningkatkan kemaslahatan bersama, baik untuk pengembangan khazanah metodologi PkM itu sendiri maupun upaya nyata ikut memajukan khalayak sasaran.

\section{Saran}

Mengingat masih banyaknya kelembagaan PAUD di daerah "kantong-kantong ketertinggalan sosial" di jantung kota Surabaya yang memerlukan pemberdayaan berbasis komunitas setempat, ke depannya, disarankan agar bentuk-bentuk kegiatan yang bertujuan mengangkat drajat kualitas sosial di "kantong-kantong ketertinggalan sosial" di jantung kota Surabaya, antara lain seperti yang telah dilaksanakan oleh Tim Penggagas dan Pelaksana Kegiatan PkM Prodi Sastra Inggris U.K. Petra ini bisa dipahami dan diberi dukungan untuk keterlaksanaannya.

\section{UCAPAN TERIMA KASIH}

Patut disyukuri bahwa Kegiatan Pengabdian kepada Masyarakat (PkM) dana hibah DIKTI 2015 yang berjudul " $\mathrm{I}_{b} \mathrm{M}$ Pelestarian Kearifan Lokal Melalui Pelatihan Mendongeng bagi Bunda P.A.U.D Kelurahan Dr. Soetomo, Surabaya”, telah bisa dilaksanakan dengan baik dari bulan Mei sampai Juli 2015. Tim Penggagas dan Pelaksana PkM ini mengucapkan terima kasih kepada pihakpihak yang memungkinkan kegiatan $\mathrm{PkM}$ ini terlaksana dengan baik, antara lain:

1. Bapak Jahuri Sugianto, S.Sos., Lurah Kelurahan Dr. Soetomo, Surabaya, yang sangat mengapresisasi kegiatan PkM ini dari tahap perencanaan sampai pelaksanaannya.

2. Bapak Gunawan, Wakil Lurah Kelurahan Dr. Soetomo, Surabaya, yang banyak memberi bantuan dan dukungan moral pada taraf perencanaan pelaksanaan kegiatan abdimas.

3. Bapak Ketua R.W. 3, Kelurahan Dr. Soetomo, yang memungkinkan pelaksanaan kegiatan $\mathrm{PkM}$ berjalan secara lancar dan tertib di Balai RW 3.

4. Para Bunda P.A.U.D di lingkup Kelurahan Dr. Soetomo, yang sangat dedikatif dalam Pembinaan karakter anak-anak PAUD di komunitas sasaran.

5. U.K. Petra, khususnya Staf Pusat Pengabdian kepada Masyarakat, yang banyak membantu dari saat perencanaan, pelaksanaan, dan sampai pelaporan hasil kegiatan.

6. DIKTI yang telah memberikan dukungan Dana Hibah th. 2015 sehingga kegiatan PkM yang dilaporkan di sini bisa diwujudkan.

Akhirnya, tidak ada gading yang tidak retak. Tim Penggagas dan Pelaksana PkM terbuka untuk menerima kritik-kritik yang membangun sehingga ke depannya bisa menghasilkan bentuk-bentuk kegiatan PkM yang lebih berhasil-guna dan berdaya-guna bagi penerapan Iptek tepat guna untuk perkembangan masyarakat pada umumnya.

\section{DAFTAR PUSTAKA}

Balai Melayu. (2014). Tumbuhkan lagi budaya mendongeng. Diunduh 15 Februari, 2014 dari $<$ http://ceritarakyatnusantara.com/id/news/246Tumbuhkan-Lagi-Budaya-Mendongeng> 
Bimo. (2010) Teknik bercerita untuk anak usia dini. Diunduh 20 Januari 2014 dari <http:/badkomergangsan.wordpress.com/2010/3/20/teknik -bercerita-untuk-anak-usia-dini-kak-bimomaster-dongeng-indonesia/>

Husnaini, N. (2011). Pudarnya budaya mendongeng. Diunduh 20 Januari, 2014 dari <http://ceri tarakyatnusantara.com/id/article/70- PudarnyaBudaya-Mendongeng>

Itadz. (2008). Cerita untuk Anak Usia Dini. Yogyakarta: Tiara Wacana.

Jaenudin, A. 3 April, 2008. Membangun karakter. Diunduh 10 ebruari 2014 dari <http://www. goodreads.com/story/show/14092>.
Kementerian Pendidikan Nasional. 2001. Pedoman Pelaksanaan Pendidikan Karakter. Badan Penelitian dan Pengembangan Kurikulum, Pusat Kurikulum dan Perbukuan. 2011. http://pendikar.dikti.go.id/gdp/wp-ontent/uploads/ Pedoman-pelaksanaan-Pendikar-18-Feb2011.pdf. Diunduh 10 Pebruari 2014.

Kusuma, M. dan Suwarna, B. (2011) Mendongeng di era digital. Diunduh 25 Oktober 2013 dari $<$ http://ceritarakyatnusantara.com/id/article/68Mendongeng-di-Era-Digital>

Lickona, T. 1991. Education for Character: How our Schools can Teach Respect and Responsibility. New York: Bantam. 